\title{
A Transcript Finishing Initiative for Closing Gaps in the Human Transcriptome
}

\author{
The Ludwig-FAPESP Transcript Finishing Initiative, ${ }^{1}$ Mari Cleide Sogayar, ${ }^{2}$ and \\ Anamaria A. Camargo ${ }^{2}$
}

\begin{abstract}
We report the results of a transcript finishing initiative, undertaken for the purpose of identifying and characterizing novel human transcripts, in which RT-PCR was used to bridge gaps between paired EST clusters, mapped against the genomic sequence. Each pair of EST clusters selected for experimental validation was designated a transcript finishing unit (TFU). A total of 489 TFUs were selected for validation, and an overall efficiency of $43.1 \%$ was achieved. We generated a total of 59,975 bp of transcribed sequences organized into 432 exons, contributing to the definition of the structure of 211 human transcripts. The structure of several transcripts reported here was confirmed during the course of this project, through the generation of their corresponding full-length cDNA sequences. Nevertheless, for $21 \%$ of the validated TFUs, a full-length cDNA sequence is not yet available in public databases, and the structure of $69.2 \%$ of these TFUs was not correctly predicted by computer programs. The TF strategy provides a significant contribution to the definition of the complete catalog of human genes and transcripts, because it appears to be particularly useful for identification of low abundance transcripts expressed in a restricted set of tissues as well as for the delineation of gene boundaries and alternatively spliced isoforms.
\end{abstract}

[Supplemental material is available online at www.genome.org. The sequence data from this study have been submitted to GenBank under accession nos. CF272536-CF272733.]

A primary objective of the Human Genome Project has been the identification of the complete set of human genes and their derived transcripts. A major step towards this goal was achieved at the beginning of 2001 with the publication of two independent draft versions of the human genome sequence and the identification of $>30,000$ genes (Lander et al. 2001; Venter et al. 2001). However, it became apparent that extracting exonic sequences directly from the human genome is not straightforward and that a variety of complementary strategies are required for gene identification and characterization.

In this context, microarrays (Penn et al. 2000; Dennis 2001; Schoemaker et al. 2001; Kapranov et al. 2002) and sequence comparisons with other organisms at an appropriate evolutionary distance (Batzoglou et al. 2000; Roest et al. 2000) constitute powerful preliminary approaches to identifying transcribed regions within the genome sequence. Nevertheless, transcript sequencing is necessary both for the final proof of the existence of an expressed gene and for the precise identification of intron/exon boundaries and alternatively spliced forms (Camargo et al. 2002).

A full-length cDNA sequence, ideally including a transcription initiation site and a polyadenylation site, is the gold standard for transcript definition. Considerable progress has been made in the generation of representative full-length cDNA sequences (Strausberg et al. 1999, 2002; Wiemann et al. 2001; Kikuno et al. 2002; Nakajima et al. 2002), especially following the development of sophisticated protocols for obtaining full-length transcript molecules and to correct for transcript expression bias (Bonaldo et al. 1996, Carninci et al. 2000).

Expressed sequence tags (ESTs) are another major source of transcript sequence. ESTs either are single-pass, partial sequences

\footnotetext{
${ }^{1}$ A complete list of authors appears at the end of this manuscript. ${ }^{2}$ Corresponding authors. E-MAIL anamaria@compbio.ludwig.org.br; FAX 55-11-3207-7001. E-MAIL mcsoga@iq.usp.br; FAX 55-11-3091-3820.

Article and publication are at http://www.genome.org/cgi/doi/10.1101/ gr.2111304. Article published online before print in June 2004.
}

derived either from the $5^{\prime}$ and $3^{\prime}$ extremities of cDNA clones (Adams et al. 1991) or are specifically directed towards the central coding regions of transcripts, in the case of open reading frame ESTs (ORESTES; Dias et al. 2000; Camargo et al. 2001). Initially, ESTs were exploited as a source for gene discovery (Adams et al. $1992,1993)$, but they have also been widely used to build tissuespecific transcript profiles (Bortoluzzi et al. 2000a,b,c; Huminiecki and Bicknell, 2000; Phillips et al. 2000; Yu et al. 2001; Katsanis et al. 2002; Megy et al. 2003), to construct gene-based physical maps (Hudson et al. 1994), to compare genomes of different organisms (Tugendreich et al. 1994; Lee et al. 2002), to accurately identify transcripts in genomic sequences (Bailey et al. 1998; Jiang and Jacob 1998; Kan et al. 2001), and to study aspects of mRNA structure, such as splicing variants (Hide et al. 2001; Modrek et al. 2001; Clark and Thanaraj 2002; Kan et al. 2002; Xie et al. 2002; Xu et al. 2002; Wang et al. 2003), alternative polyadenylation (Gautheret et al. 1998; Beaudoing and Gautheret 2001; Iseli et al. 2002), and single nucleotide polymorphisms (Garg et al. 1999; Picoult-Newberg et al. 1999; Clifford et al. 2000; Irizarry et al. 2000; Hu et al. 2002).

To date, $>5,200,000$ human ESTs have been generated from different organs and tissues, deriving mainly from the Merck Gene Index Project (Williamson 1999), the Cancer Genome Anatomy Project (CGAP; Strausberg et al. 2000), and the Human Cancer Genome Project Ludwig/FAPESP (HCGP; Dias et al. 2000; Camargo et al. 2001). Nevertheless, it is widely recognized that EST databases are subjected to artifacts related to the partial, lowquality nature of the sequences and the presence of various kinds of contamination (Sorek and Safer 2003). In addition, because of the large differences in abundance between RNA species, the coverage of individual transcripts by ESTs is highly variable. Despite that, it is believed that the vast majority of transcripts have been sampled at least once by either a full-length cDNA or EST sequence (Ewing and Green 2000; Liang et al. 2000).

Although the amount of transcript data currently available is not sufficient to identify all human genes, the judicious use of 
this data set, in conjunction with the draft sequences of the human genome, has been highly informative in the characterization of new human genes (Reymond et al. 2002; Silva et al. 2003). Here we describe the utilization of a transcriptome database to guide the generation of novel human transcript sequences on a genome-wide basis. By using the genomic sequence as a scaffold for EST mapping and clustering, we have used RT-PCR to bridge gaps between EST clusters that we judged as likely to be derived from the same genes. The resulting novel sequence confirms that the ESTs from different clusters are, in fact, derived from a common transcript and defines the intervening region between them.

Because this process is very similar to the finishing phase of genome projects, we called it transcript finishing (TF). This powerful, albeit laborious, approach allows the characterization of novel human transcripts and splicing isoforms, which appear to be generally expressed at a low abundance level and/or in a restricted set of tissues and avoids the necessity of a full-length cDNA clone in order to confirm the structure of a gene.

\section{RESULTS}

\section{Generation of the Transcriptome Database and EST Cluster Selection for Experimental Validation}

We have used the publicly available human genome and transcript sequences to identify and experimentally validate addi- tional transcribed regions in the human genome. The two data sets were integrated into the transcriptome database by using the BLASTN program to map all transcript sequences onto the assembled version of the human genome available from the National Center for Biotechonology Information (NCBI). We have also mapped to the genome, using the raw data generated by EST sequencing projects, a set of trusted 3 'tags that provide unique identifiers for transcript 3 ' ends (Iseli et al. 2002). The tags were used for positional orientation and as a start point for transcript reconstruction. To facilitate visualization of the alignments and the access to information such as project and tissue source of the sequences, alignment scores, and the position of 3'tags, a graphical interface was also developed (Fig. 1).

We identified 244,148 human transcript clusters, of which 14,598 contained at least one full-length cDNA sequence, and 229,550 clusters that were composed exclusively of partial transcript sequences. Of the set of 14,598 clusters containing fulllength sequences, 13,149 (90\%) had at least one corresponding EST, and the remaining 1449 (10\%) were composed only of fulllength cDNA sequences. These data demonstrate that, despite the fact that $>5$ million EST sequences are available, they do not fully cover the human transcriptome and that the generation of additional transcribed sequences is still required.

It is noteworthy that clusters composed exclusively by ESTs have a reduced number of sequences (average, 5.9 sequences) derived from fewer different tissues (average, 3.0), compared with clusters containing a full-length cDNA, which have an average of

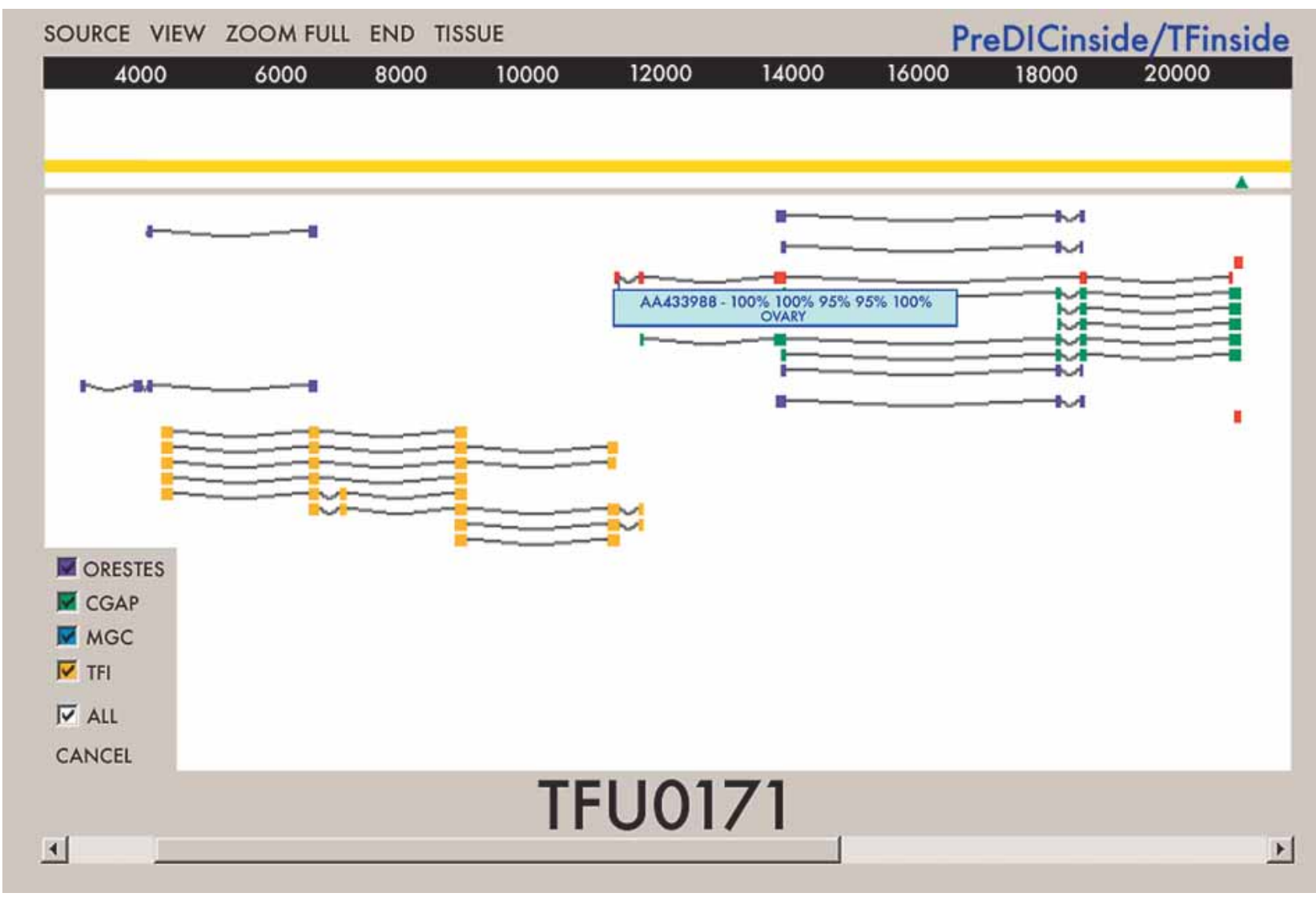

Figure 1 TFI graphical interface. The TFI graphical interface displays a region of the human genome sequence as a yellow line, with a scale in base pairs (bp). Expressed sequence tags (ESTs) that align with the genome sequence are shown in different colors, depending on the project of origin: ORESTES from the FAPESP/LICR Human Cancer Genome Project in purple; CGAP in green, MGC in blue, and TFI in yellow, with splicing structures represented as gray lines. The interface shows an experimentally validated TFU (number 171) joining two EST clusters. The TFI interface also provides information on the tissue of origin of the transcript sequences, the percentage of similarity of each exon with the human genome sequence, and the presence of 3' tags represented as green triangles.

\section{Genome Research}

www.genome.org 
65.5 sequences derived from eight different tissues. Based on these observations, we conclude that the human transcripts that remain to be defined are expressed at low levels in a restricted set of tissues and that their characterization will benefit from a direct approach such as the TF.

Because EST databases contain a significant fraction of artifactual and contaminant sequences, we selected, for experimental validation, pairs of clusters that consist of ESTs that align noncontiguously to the genome, consistent with the presence of a splicing structure. We also restricted our validation to pairs of clusters that map at a maximum distance of $10 \mathrm{~kb}$ from each other, in order to increase the probability that these clusters belong to the same transcript. By using these criteria, a total of 2373 pairs of clusters $(-2 \%$ of the total number of clusters composed of partial sequences) were initially selected and subjected to manual inspection using our graphical interface.

Manual inspection allowed the assessment of similarity and extension of the alignments, as well as the position of the selected pair of clusters relative to the 3 'tags. Following this procedure, a subset of 489 pairs of clusters was initially selected for experimental validation. The number of clusters eliminated by manual inspection was very low; therefore, the 489 pairs of clusters selected for experimental validation can be considered an unbiased sample of the 2373 initially selected clusters. Clusters selected for validation were separated from each other by an average $2879 \mathrm{bp}$ of intervening genomic sequence and were composed by an average of 5.92 EST sequences derived from an average of three distinct tissues. Each pair of EST clusters selected for experimental validation was designated as a single TF unit (TFU). Information related to the 489 TFUs selected for validation can be accessed at http://200.18.51.201/viewtfi.

\section{Experimental Validation and the Generation of New Transcribed Sequences}

A general overview of the computational and experimental validation strategies is presented in Figure 2. A total of two coordi- nation groups, four bioinformatics groups, and 29 validation laboratories, linked through the Internet, participated in the computational and experimental phase of the project (http:// 200.18.51.201/transcript/Participants.html). Following cluster selection and manual inspection, primers for RT-PCR validation of each TFU were designed automatically. The genomic sequence was chosen as a template for primer design because it is generally of a higher quality than are EST sequences. cDNA preparation was also a critical issue, because both the quality and the representation of different tissues directly influence the validation efficiency. As an indicator of genomic DNA contamination, the total RNA preparations were subjected to PCR amplification by using primers within intronic sequences flanking the exon 12 of the MLH1 gene and found to be negative. The quality of the cDNA product was demonstrated by PCR amplification of sequences located at the $5^{\prime}$ extremity of the NOTCH2 transcript (a long transcript of $11.4 \mathrm{~Kb}$ ). A total of $22 \mathrm{cDNA}$ preparations, derived from a number of cell lines and representing 18 distinct tissues, were used.

The total of 3019 sequences, generated during the project, was subjected to an automated cleaning protocol. High-quality sequences were aligned against the genomic sequence, and the alignment coordinates and scores for validated sequences were loaded into the transcriptome database and displayed on the graphical interface (Fig. 1). We successfully validated 211 of the 489 TFUs that were distributed, yielding an overall validation efficiency of $43.1 \%$.

A single pair of primers was tested for each TFU, and experimental validation was undertaken in a high-throughput singlepass format. Few modifications were adopted when a positive amplification was not achieved (see Methods). To estimate the false-negative amplification rate of the TF strategy, we determined the number of the nonvalidated TFUs for which a fulllength cDNA sequence had been made available by other sequencing projects during the course of our project. For 40 of the nonvalidated TFUs, we were able to identify a full-length sequence linking the two EST clusters initially selected for validation. Thus, these cases can be considered to be false-negative amplifications. For 118 of the nonvalidated TFUs, the existence of a full-length sequence matching just one of the two selected clusters allowed us to conclude that the two clusters were in fact part of different transcripts. For these cases, the absence of an RT-PCR product thus reflects true negatives. For the 120 of the remaining nonvalidated TFUs, a conclusive result could not identify any corresponding fulllength sequence. Therefore, based on these results, we can estimate that the rate of false-negative amplifications in the TF strategy is $\sim 25 \%$ (40/158 nonvalidated TFUs).

In addition, to identify variables related to the expression pattern of the novel transcripts that influence the efficiency of validation, two sets composed of 174 validated TFUs and 208 nonvalidated TFUs were compared. As shown in Table 1, the validated TFUs had, on average, more ESTs in each cluster derived from a larger number of different tissues. Both of these differences were statistically significant according to Mann-Whitney tests, indicating that a higher expression level and a broader expression pattern of the selected transcripts
Figure 2 General scheme of the TFI strategy. Schematic outline of the strategy used for computational and experimental validation of TFU sequences. Following the development of bioinformatics tools, the generation of the transcriptome database, and automatic cluster selection, the project tasks were divided between the coordination and the validation laboratories.
Genome Research 
Table 1. Comparison Between Validated and Nonvalidated TFUs

\begin{tabular}{lccc}
\hline & $\begin{array}{c}\text { Validated TFUs } \\
\text { (Std deviation) }\end{array}$ & $\begin{array}{c}\text { Nonvalidated TFUs } \\
\text { (Std deviation) }\end{array}$ & $\boldsymbol{P}$ value \\
\hline Average distance between clusters & $2609(3202)$ & $3105(2942)$ & 0.008 \\
Average no. of ESTs in each cluster & $6.10(8.91)$ & $5.77(13.23)$ & 0.010 \\
Average no. of distinct tissues in each cluster & $3.45(4.27)$ & $2.85(4.54)$ & 0.002 \\
Presence of a common tissue in both clusters & Yes 63 & Yes 62 & 0.223 \\
& No 111 & No 146 & \\
\hline
\end{tabular}

favored validation. The presence of ESTs derived from the same tissue in both clusters did not influence the likelihood of validation according to $\chi^{2}$ tests.

A total of $59,975 \mathrm{bp}$ of transcribed sequence, organized into 432 exons, were generated, contributing to the definition of the structure of 211 distinct human transcripts. Each validated TFU had a mean of $281.6 \mathrm{bp}$ and a median of $207 \mathrm{bp}$ of novel sequence not represented by the original EST clusters and a mean of 2.03 and a median of two newly defined exons. The validated TFU sequences have been submitted to GenBank under the accession numbers CF272536 to CF272733, which are provided as Supplemental Table 1.

\section{Consensus Sequences Generation and Annotation of the Validated Human Transcripts}

Consensus sequences produced by assembling the sequences derived from the validation fragment and the sequences from all ESTs in both clusters were obtained for 186 of the 211 validated TFUs. Assembly of a consensus sequence was not possible for 25 TFUs, due mainly to the presence of repetitive sequences and alternative splicing forms. Consensus sequences, with an average of $1240 \mathrm{bp}$, can be accessed at (http://200.18.51.201/ viewconsensus/).

Consensus sequences derived from the validated TFUs were aligned to the July 2003 version of human genome sequence assembly provided by the University of California, Santa Cruz (UCSC), using the BLAT search tool (http://genome.ucsc.edu/cgibin/hgBlat) to compare the validated consensus sequences with known genes and gene predictions (Table 2). A significant fraction $(68.8 \%)$ of the validated transcripts completely overlapped with the alignment coordinates of a known gene or full-length human mRNA submitted to the GenBank during the course of our project (Fig. 3A), and a smaller fraction (10.2\%) represented extensions (mostly $5^{\prime}$ ) to partial cDNA sequences deposited in public databases (Fig. 3B). However, for $21 \%$ of the validated TFUs, a full-length cDNA sequence was not available in public databases as of July 2003. The structure of the majority (69.2\%) of the validated TFUS without a corresponding full-length cDNA

Table 2. Annotation of Validated Consensus

\begin{tabular}{lcc}
\hline Categories & $\begin{array}{c}\text { Number of } \\
\text { consensus } \\
\text { sequences }\end{array}$ & $\begin{array}{c}\text { Percentage } \\
(\%)\end{array}$ \\
\hline Known gene & 128 & 68.8 \\
Extension of a known gene & 19 & 10.2 \\
New transcript w/total prediction & 12 & 6.5 \\
New transcript w/partial prediction & 15 & 8.0 \\
New transcript w/o prediction & 12 & 6.5 \\
Total & 186 & 100 \\
\hline
\end{tabular}

\section{Genome Research \\ 1416 Genome Researc
www.genome.org}

sequence had not been correctly predicted by ab initio gene prediction programs such as Fgenesh++, Geneid, and GenScan. These TFUs can thus be considered as new human transcripts.

The consensus sequences corresponding to new human transcripts were further characterized by BLASTX analysis, and protein domains were predicted by using the Pfam and Prosite databases. Of the 39 consensus sequences representing new human transcripts, $27(69.2 \%)$ contained an ORF of at least 100 amino acids, and eight (20.5\%) contained a clearly defined protein domain including three IG-like domains and a protein kinase. Complete information on the characterization of the validated TFUs, including consensus size, annotation, chromosomal location, and expression pattern based on ESTs distribution, are provided as Supplemental Table 2.

The validated transcripts that completely overlapped with the alignment coordinates of a known gene containing a defined ORF were used to estimate the percentage of consensus sequences that represent complete transcripts. Only a small fraction $(9.7 \%)$ of the 93 validated TFUs analyzed contained a complete ORF. The low percentage obtained was expected because, in the TF strategy, RT-PCR is used to brigde gaps between partial transcript sequences.

\section{Identification and Experimental Validation of Alternatively Spliced Isoforms}

Several reports have suggested that at least $30 \%$ to $35 \%$ of human genes undergo alternative splicing (Brett et al. 2000; Modrek et al. 2001); nevertheless, this value is probably underestimated because many cell types have not yet been fully explored by cDNA sequencing. The use of different cDNA sources during the experimental validation phase of the new human transcripts allowed us to identify many new splicing variants. We explored the degree of sequence variability due to alternative splicing in the set of 186 consensus sequences that we generated and found evidence for alternative splicing in $22(12 \%)$ cases (Table 3). Intron retention was observed in 11 TFUs, and alternative exon usage was detected in 11 of the 22 TFUs with alternative splicing. Conserved GT-AG splice junctions were present in all TFUs with alternative exon usage. The possibility of genomic DNA contamination, in those cases in which we have observed the retention of an intron, was excluded due to the presence of processed introns in the same cDNA molecule containing the retained intron. Moreover, the RNAs used for experimental validation of the alternatively spliced forms have been treated with DNase and tested for the absence of intronic sequences, as described in Methods.

We selected six TFUs with alternative exon usage, representing a total of 14 splicing isoforms, for further experimental validation. Each pair of primers used for experimental validation of the alternatively spliced forms was assayed against all $22 \mathrm{cDNA}$ sources, without pooling. Touchdown PCR confirmed 10 (83\%) of the putative investigated isoforms. No PCR amplification was achieved for one TFU. Some splicing isoforms were expressed in 


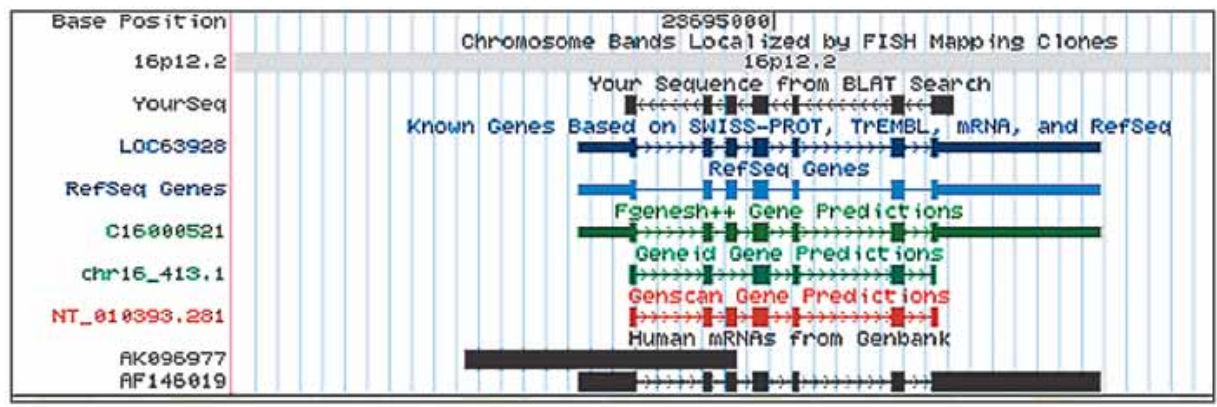

\section{TFU0023}

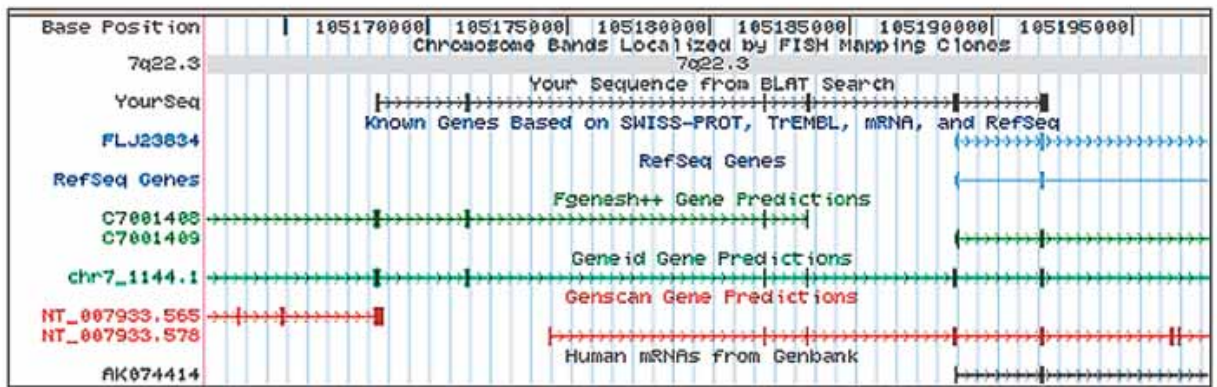

\section{TFU1102}

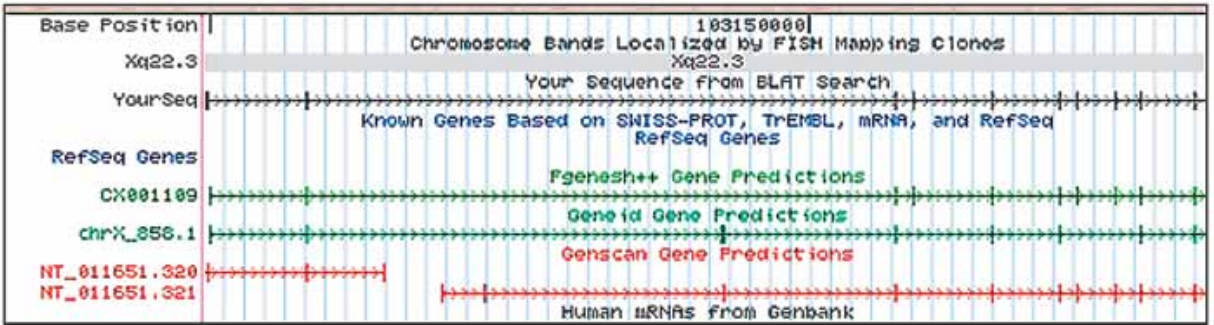

\section{TFU1013}

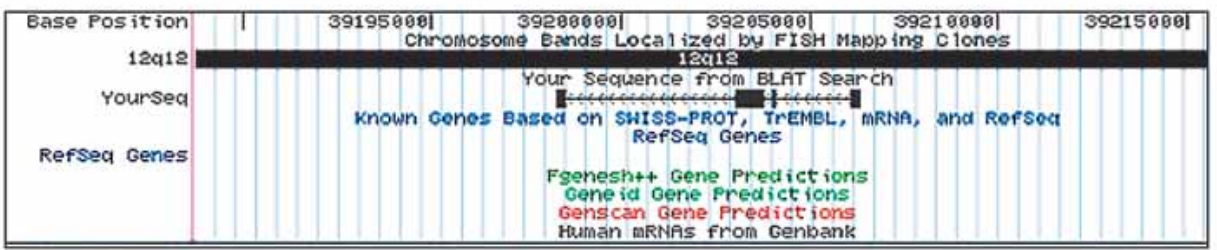

\section{TFU0125}

Figure 3 Characterization and annotation of validated TFUs. Alignment of four consensus sequences, derived from the validated TFUs, to the July 2003 version of the UCSC human genome sequence assembly, using the BLAT search tool. (A) TFU00023 corresponds to YourSeq (black) completely overlapping with known genes based on SWISS-PROT, TrEMBL, MRNA, and RefSeq (dark blue). (B) TFU01102 represents a 5' extension of a partial cDNA (FLJ23834). (C) TFU01013 represents a new human transcript structure that was correctly predicted by ab initio gene predition transcripts, such as Fgenesh++ (green). (D) TFU00125 represents a new human transcript with no predicted transcripts described by gene prediction programs.

a restricted pattern, being detected in one or a few of the tissues analyzed by RT-PCR (data not shown). None of these splicing isoforms had been previously identified, highlighting the potential use of the TF strategy for uncovering the genetic variability generated at the transcriptome level.

A typical example of this experimental validation is illustrated in Figure 4. In this case, we were able to identify two alternative exons, one of which presents an extra exon of $138 \mathrm{bp}$ and the other a 21-bp extension of an exon already represented by EST sequences. The possible combination of these variants results in four splicing isoforms. Figure 4 shows a 388-bp product (obtained with primers P1 and P2) corresponding to the prototype isoform, a 370-bp product (primers $\mathrm{P} 2$ and $\mathrm{P} 3$ ) corresponding to the isoform containing the additional exon, a 314-bp product (primers $\mathrm{P} 1$ and $\mathrm{P} 4$ ) corresponding to the isoform with the extended exon, and a 452-bp product corresponding to the isoform containing both the additional exon and the extended exon.

\section{DISCUSSION}

Currently, intense activity is directed toward defining the complete set of genes and their derived transcripts in the human genome. This information will have a profound impact in diverse areas of biology such as human evolution, structural genomics, and medicine. However, because of the highly dispersed and complex structure of human genes, it is extremely difficult to correctly identify transcribed regions within the genome (Camargo et al. 2002).

Estimates based on gene prediction both within individual finished chromosomes (Dunham et al. 1999; Hattori et al. 2000), as well as in the draft human genome sequences (Lander et al. 
Table 3. Alternative Splicing Forms Within Validated TFs

\begin{tabular}{|c|c|c|c|c|}
\hline $\begin{array}{l}\text { Validated } \\
\text { consensus }\end{array}$ & $\begin{array}{l}\text { Type of } \\
\text { alternative } \\
\text { splicing }\end{array}$ & $\begin{array}{c}\text { Presence of } \\
\text { conserved } \\
\text { acceptor } \\
\text { and donor } \\
\text { sites }\end{array}$ & $\begin{array}{l}\text { No. of } \\
\text { alternative } \\
\text { isoforms }\end{array}$ & $\begin{array}{c}\text { No. of } \\
\text { validated } \\
\text { isoforms }\end{array}$ \\
\hline TFU0118 & Exon usage & Yes & 2 & 1 \\
\hline TFU0200 & Exon usage & Yes & 4 & 4 \\
\hline TFU0274 & Exon usage & Yes & 2 & 2 \\
\hline TFU0351 & Exon usage & Yes & 2 & 2 \\
\hline TFU1004 & Exon usage & Yes & 2 & 1 \\
\hline TFU1058 & Exon usage & Yes & 3 & 0 \\
\hline TFU0155 & Exon usage & Yes & 2 & nd \\
\hline TFU0238 & Exon usage & Yes & 2 & nd \\
\hline TFU0308 & Exon usage & Yes & 2 & nd \\
\hline TFU0003 & Intron retention & nd & nd & nd \\
\hline TFU0019 & Intron retention & nd & nd & nd \\
\hline TFU0035 & Intron retention & nd & nd & nd \\
\hline TFU0052 & Intron retention & nd & nd & nd \\
\hline TFU0099 & Intron retention & nd & nd & nd \\
\hline TFU0112 & Intron retention & nd & nd & nd \\
\hline TFU0125 & Intron retention & nd & nd & nd \\
\hline TFU0131 & Intron retention & nd & nd & nd \\
\hline TFU0209 & Intron retention & nd & nd & nd \\
\hline TFU0285 & Intron retention & nd & nd & nd \\
\hline TFU0371 & Intron retention & nd & nd & nd \\
\hline TFU0148 & Exon skipping & nd & nd & nd \\
\hline TFU1061 & Exon skipping & nd & nd & nd \\
\hline
\end{tabular}

$\mathrm{nd}=$ not done.
2001; Venter et al. 2001), have uniformly concluded that the human genome possesses $<35,000$ genes. This number has been supported by a preliminary analysis of EST coverage of known genes (Ewing and Green 2000) as well as comparative genomics analysis (Roest et al. 2000). Most of these 35,000 genes are already represented by a full-length cDNA sequence in transcript databases. In UniGene (http://www.ncbi.nlm.nih.gov/entrez/ query.fcgi? $\mathrm{db}=$ unigene), for example, there are currently 28,412 transcript clusters represented by at least one full-length cDNA sequence.

Here we have proposed and validated the use of the TF strategy for characterization of new human transcripts that are only partially represented by ESTs. Because EST databases contain a significant fraction of artifactual and contaminant sequences, we selected pairs of clusters for experimental validation that exhibited a clear splicing structure when aligned to the genome. By requiring the occurrence of splicing, the level of contamination in the EST databases is significantly reduced, although at the expense of eliminating many genuine $3^{\prime}$ ESTs. The selection criteria used in our initial analysis are very restrictive, and the adoption of less stringent criteria (including clusters without a splicing structure) will certainly be required to complete the catalog of human genes using the strategy we described. Given the 2373 initially selected clusters, of which 489 were subjected to experimental validation, 1884 pairs of clusters remain to be validated. If we assume an overall validation efficiency of $43 \%$, we can estimate that the TF strategy might contribute to the definition of at least 791 additional genes in the human genome.

Several factors may have influenced our validation efficiency, including experimental limitations related to primer and cDNA synthesis, the particular characteristics of human transcripts such as low expression level, and the existence of a significant proportion of sense-antisense transcriptional units on opposite DNA strands of the same genomic locus (Yelin et al 2003). A $25 \%$ false-negative amplification rate was estimated for the TF strategy and is probably related to the high-throughput single-pass format adopted for the experimental validation. In this context, the use of additional primer pairs and modifications of cycling parameters that would favor the amplification of difficult targets could be added to the process to reduce the negative amplification rate.

We found that validation efficiency was enhanced by implementation of quality controls for cDNA synthesis, the use of polyA+-derived cDNA, a combination of both oligo dT and random primers for cDNA synthesis, and also the use of nested RTPCR. We also observed that validated pairs of clusters had a higher average number of ESTs per cluster and a higher number of different tissues represented by the clusters compared with pairs of clusters that we were not able to validate. Validated TFUs had, on average, 6.1 ESTs in each cluster derived, on average, from 3.45 distinct tissues. Noteworthy, in $41 \%$ of the validated TFUs, one of the two EST clusters was composed of a single EST, and in $13 \%$ of the cases, both clusters corresponded to singleton ESTs, indicating the often overlooked importance of this kind of data.

For a reasonable fraction (21\%) of the validated TFUs, a fulllength cDNA sequence was not yet available in public databases. The structure of the majority $(69.2 \%)$ of these validated TFUs had not been correctly predicted by ab initio gene prediction programs and, consequently, was not annotated in the human genome. In addition, the use of different cDNA sources in the validation process allowed us to identify many splicing variants that were further validated by RT-PCR. As for $21 \%$ of validated sequences, none of these splicing variants had been previously identified.

We conclude that the TF strategy provides a convenient and unique means for delineating gene boundaries and new transcribed sequences. The TF strategy permits the characterization of new human transcripts and splicing isoforms expressed at a low level and in a restricted set of tissues and will certainly continue to contribute to the definition of the complete catalog of human genes and transcripts.

\section{METHODS}

\section{Cell Culture}

Human cell lines were obtained from the American Type Culture Collection (ATCC) and cultured as recommended (http:// www.atcc.org). The following cell lines were used in order to generate a cDNA panel representing different tissues: A172 glioblastoma; T98G multiform glioblastoma; FaDu squamous cell carcinoma; SW480 colorectal adenocarcinoma; Skmel-25 malignant melanoma; DU145 prostate carcinoma; HeLa cervix adenocarcinoma; XP Xeroderma pigmentosum fibroblasts; ZR-75-1, MCF-7, and Hs578T breast ductal carcinoma; IM9 B transformed lymphoblasts; TT thyroid carcinoma; U937 histyocytic lymphoma; Hs1.Tes normal testis; Hs732.PL normal placenta; Hep G2 hepatocarcinoma; NCI-H1155 and H358 lung carcinoma; SCaBER urinary bladder carcinoma; SAOS 2 osteosarcoma; and Tu-rim primary culture of a kidney tumor.

\section{RNA Extraction and cDNA Synthesis}

Total RNA was prepared from cultured cells seeded in four 150mm-diameter (P150) plates by using the cesium chloride cushion technique (Chirgwin et al. 1979). Poly A ${ }^{+}$RNA was isolated from $200 \mu \mathrm{g}$ total RNA with the PolyAttract mRNA isolation kit (Promega), and the total yield of this purification was used for cDNA synthesis. For cDNA synthesis, 100 to $200 \mu \mathrm{g}$ total RNA or the corresponding purified mRNA were treated with $100 \mathrm{U}$ DNAse I (FPLC-pure, Amersham) and reverse-transcribed by using oligo(dT)12-18, random primer and SuperScript II (Invitrogen), following the manufacturer's instructions. The resulting cDNA was then subjected to RNase $\mathrm{H}$ treatment and distributed among the

\section{Genome Research}



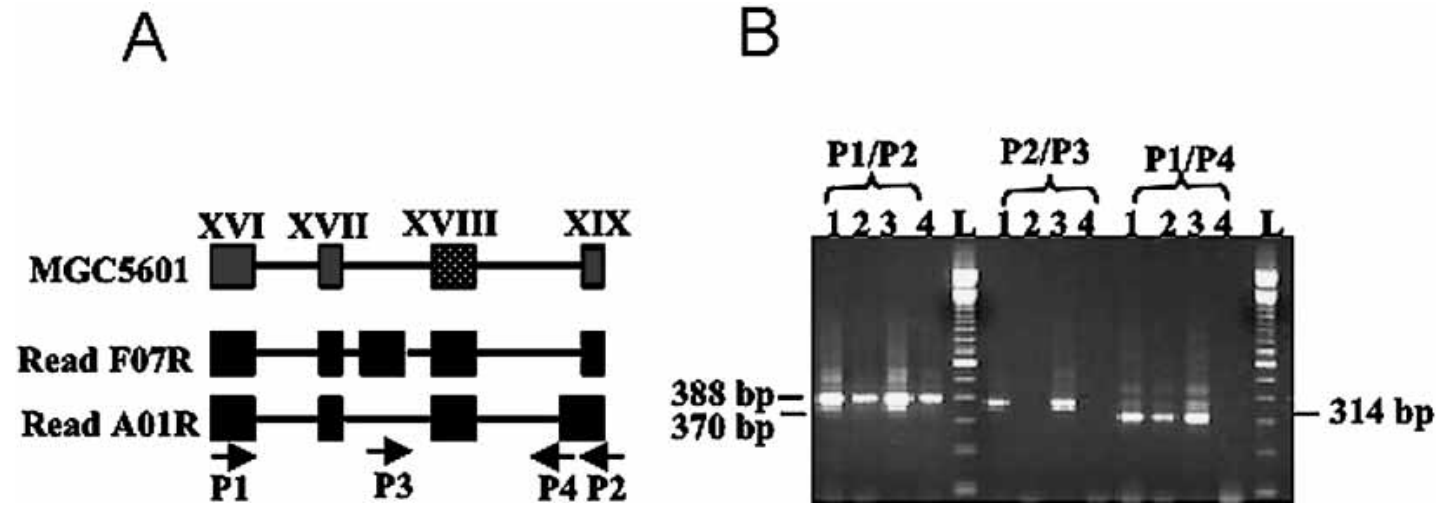

Figure 4 Experimental validation of MGC5601 gene alternative splicing isoforms. (A) Gene structure for exons XVI-XIX (boxes) of the MGC5601 gene located on chromosome 12. Introns are represented by lines. Two alternative exons are shown on TFU reads, and a hypothetical combination of these two exons is also shown. Sequence F07R has an extra exon between exon XVII and XVIII. Sequence A01R has an extended exon XIX. Four primers were designed for validation tests, as indicated in the figure (P1-P4), and each pair of primers were assayed against all 22 cDNA preparations without pooling. (B) We detected all four of these alternative splicing isoforms in MGC5601. Numbers one through four indicate the tissues from which the cDNA was obtained (1, multiform glioblastoma; 2, glioblastoma; 3, prostate carcinoma; and 4, primary kidney cell culture). The sizes of the bands obtained are indicated. $L$ indicates 100 -bp ladder.

31 validation laboratories involved in the project. The quality of the cDNA synthesis and the absence of genomic DNA contamination were evaluated for each preparation. Total RNA was subjected to PCR amplification by using primers within intronic sequences flanking exon 12 of the MLH1 gene (forward, 5'TGGTGTCTCTAGTTCTGG-3'; reverse, 5'-CATTGTTGTAG TAGCTCTGC-3'). The quality of the cDNA product was also tested by PCR amplification of sequences located at the $5^{\prime}$ extremity of the NOTCH2 transcript (a long transcript of $11.4 \mathrm{~Kb}$; forward, 5'-ACTGTGGCCAACCAGTTCTC-3'; reverse, 5-' CTCT CACAGGTGCTCCCTTC-3').

\section{RT-PCR and Sequencing}

RT-PCR was carried out in $25 \mu \mathrm{L}$ reaction mixtures containing 1 $\mu \mathrm{L}$ cDNA, $10 \times$ Taq DNA polymerase buffer, $200 \mu \mathrm{M}$ dNTP, 6 pmoles of primers, $1.5 \mathrm{mM} \mathrm{MgCl}_{2}$, and $1 \mathrm{U}$ Taq DNA polymerase (GIBCO BRL). Standard PCR conditions were as follows: 4 min at $94^{\circ} \mathrm{C}$ (initial denaturation), $40 \mathrm{sec}$ at $94^{\circ} \mathrm{C}, 40 \mathrm{sec}$ at $55^{\circ} \mathrm{C}$, and 1 min at $72^{\circ} \mathrm{C}$ for 35 cycles and a final extension step of $10 \mathrm{~min}$ at $72^{\circ} \mathrm{C}$. Modifications of the standard protocol included annealing temperature, $\mathrm{MgCl}_{2}$ concentration, addition of PCR enhancers such as betaine, and the use of polymerases with hot start activity. PCR products were directly sequenced with the same primers used for RT-PCR or cloned before sequencing. If more than one fragment was obtained for the same TFU using different cDNA sources, all fragments were sequenced. This was also the case if multiple bands were obtained in PCR amplifications using a single cDNA source. Sequencing different fragments obtained for a specific TFU allowed us to characterize a number of alternatively spliced transcripts. Sequencing reactions were carried out by using the DYEnamic ET terminator Cycle Sequencing Kit (Amersham Pharmacia) and separated by electrophoresis using an ABI 377 Prism Sequencer (Applied Biosystems) according to supplier's recommendations.

\section{Transcriptome Database and Graphical Interface}

BLASTN was used to identify pair-wise similarities between all known transcript sequences and the draft genome sequence deposited in release 66 (March 2001) of the European Molecular Biology Laboratory (EMBL) database. Transcribed sequence data were extracted from several sources: (1) the human EST section of EMBL release 66, (2) human mRNA documented in the human section of EMBL release 66, (3) ORESTES sequences from the Ludwig Institute for Cancer Research (LICR)/FAPESP Human Cancer Genome project, and (4) human mRNAs documented in the NCBI curated RefSeq database (http://www.ncbi.nlm.nih.gov/ refseq). For genomic sequence, we used contigs of at least $10 \mathrm{~kb}$ deposited in the HUM and HTG sections. Those HTG entries that had not been fully assembled were split into individual components. Therefore, the human genome data set used is highly redundant but can easily be reduced to one of the available assemblies.

The transcript sequences were filtered for contaminants, and repetitive elements were masked out by using the PFP software package (Paracel). For each pair of matching transcribed and genomic sequences, local alignments were generated by using Sim4 (Florea et al. 1998), with parameters $\mathrm{W}=15, \mathrm{R}=0, \mathrm{~A}=4$, and $\mathrm{P}=1$. The output of Sim 4 was filtered to eliminate all alignments that did not contain at least one matching region within the genome with at least $95 \%$ identity over $30 \mathrm{nt}$. The alignment coordinates and related information were uploaded into a MySQL relational database. We used the data stored in the relational database to create clusters of transcribed sequences, based on their position within individual genomic contigs. The coordinates of the putative exons on the genome sequence were used to determine membership in a cluster. If coordinates of at least one exon were common to two transcripts, then these were considered to be part of the same cluster.

The 3' tags were generated as previously described (Iseli et al. 2002). Briefly, poly(A) or poly(T) were identified from original sequence trace files, and the 50 nucleotides immediately adjacent to it were recorded as a candidate tag (after obtaining the reverse complement for poly(T) tracts). Duplicate tags were eliminated, as were the tags matching LINE and Alu repetitive elements, ribosomal or mitochondrial sequences, and those containing simple repeats. Matches for the remaining tags were mapped to the genome, and the 50 nucleotides found downstream of the match were also recorded. Individual tags were incorporated into the MySQL database. A graphical interface was developed in TCL/ TK language in order to visualize the $3^{\prime}$ tags, EST alignments and related information, such as tissue origin and project source of the sequences.

By querying the transcriptome database, we were able to select EST clusters that do not correspond to known full-length mRNA for validation. These were at a maximum of $10 \mathrm{~kb}$ apart from each other and exhibited a clear splicing structure when aligned to the genome. Clusters selected for validation were visually inspected before ordering primers. All systems used in this work were developed by using PERL and PHP programming languages on a Linux-based server running the MySQL database management system and the Apache Web server.

\section{Cluster Selection and Primers Design}

The automated primer protocol received a fixed format file containing the accession number of the genomic clones and the 
genomic interval where the two noncontiguous EST clusters map and where the system searched for primers. A single pair of primers was designed for each TFU, which usually targeted the two exons flanking the putative gap. In a few cases, in which the presence of repetitive sequences or atypical base composition prevented the design of primers, adjacent exons were used. The Primer3 program (version 0.9) developed by the Whitehead Institute for Biomedical Research was used for primer design, adopting the following parameters: primer size of a minimum of $17 \mathrm{bp}$, optimal $18 \mathrm{bp}$ and maximum $21 \mathrm{bp}$; melting temperature of a minimum of $55^{\circ} \mathrm{C}$, optimal $60^{\circ} \mathrm{C}$ and maximum $65^{\circ} \mathrm{C}$; and GC clamp set to one. The output of Primer3 was processed in order to filter primers that had alternate annealing sites in the given genomic sequence. The system uses a Web-based interface that allows submission of files containing information on primer design, retrieval of primers found, and the modification of default parameters for primer picking.

\section{Sequence Analysis and Database Update}

Sequences were subjected to an automated protocol to (1) assess sequence quality, (2) trim vector sequences, (3) mask repetitive elements, and (4) remove undesirable sequences such as bacterial, mitochondrial, and fungi sequences. The sequence quality was determined by Phred analysis using a trimCutOff of 0.06171 (Ewing and Green 1998; Ewing et al. 1998). Sequences with $<100$ bases were excluded. Mitochondrial, bacterial, and fungi sequences were identified by BLAST searches against the GenBank entry corresponding to the human mitochondrial complete genome sequence and against a locally developed bacterial and fungal database, respectively. Significant hits were determined by using an $\mathrm{E}$ value of $10^{-5}$ for searches against mitochondrial genome and an $\mathrm{E}$ value of $10^{-30}$ for searches against bacterial databases. Masking of repetitive elements was undertaken by using the RepeatMasker (http://www.repeatmasker.org) under default parameters. The remaining high-quality sequences were aligned against the original genomic clone by using the BLASTN program, and alignment coordinates and scores were loaded into the MySQL database on a daily basis.

\section{Consensus Assembly}

The reads corresponding to validated TFs were assembled into a contig by using the PhredPhrap. The contig sequence was aligned with both EST clusters by using the BLASTN program, and alignment coordinates were used for consensus generation. A Web-based interface was developed to monitor the assembly and access the consensus sequences (http://200.18.51.201/ viewconsensus/).

\section{Characterization of Validated Transcripts}

Characterization of validated transcripts was pursued by using the UCSC Genome Browser (Kent et al. 2002), which is available at http://genome.ucsc.edu. This allowed determination of sequence overlap between the validated consensus sequences, known genes, and gene predictions. Consensus sequences derived from the validated TFUs were aligned to the July 2003 version of the human genome sequence assembly provided by UCSC using the BLAT search tool. The annotation tracks used for comparison to already known genes were known genes, RefSeq genes, and human mRNAs from the GenBank. A validated transcript was considered a new gene if its alignment coordinates did not match the coordinates of any other sequence available through the known genes, RefSeq genes, or human mRNA annotation tracks. For comparison to gene predictions, the following tracks were used: Fgenesh++, Geneid, and GenScan predictions. The prediction of individual exons instead of the full transcript prediction was considered. A validated exon was considered as predicted if it aligned within the coordinates defined by any of the three gene prediction programs (not necessarily sharing borders) and a new validated transcript was considered not predicted if all exons were not predicted by the computer programs. The consensus sequences corresponding to new validated transcripts were further characterized by BLASTX analysis, and protein domains were determined by using the Pfam and Prosite databases.

\section{Characterization and Validation of Alternatively Splicing Forms}

The individual sequences generated during the process of validation of each TFU were aligned to the human genome assembly by using the BLAT search tool, together with the final consensus sequence and representative sequences derived from both EST clusters. Alternatively spliced isoforms were visually identified by using the UCSC browser. To eliminate alignment artifacts caused by sequencing errors and problems in the genome assembly, we have considered as alternatively spliced forms only exons defined by conserved acceptor and donor splicing sites (GT/AG). Primers for validation of predicted alternative splicing isoforms were designed by using Primer3 with default parameters. The presence of alternative isoforms was analyzed by using a cDNA panel composed of 20 different normal and tumor tissues. GAPD amplification was used as a control for integrity and quantification of the RNA used for cDNA synthesis. RT-PCR products obtained in touchdown reactions were analyzed on $1.5 \%$ agarose gels.

\section{Complete List of Authors}

\section{Coordination Group Ludwig Institute}

Fabiana Bettoni, ${ }^{3}$ Dirce Maria Carraro, ${ }^{3}$ Lilian C. Pires, ${ }^{3}$ Raphael B. Parmigiani, ${ }^{3}$ Elisa N. Ferreira, ${ }^{3}$ Eloísa de Sá Moreira, ${ }^{3,32}$ Maria do Rosário D. de O. Latorre, ${ }^{4}$ Andrew J.G. Simpson, ${ }^{3}$ and Anamaria A. Camargo ${ }^{3}$

\section{Coordination Group University of São Paulo Chemistry Institute}

Luciana Oliveira Cruz, ${ }^{5}$ Theri Leica Degaki, ${ }^{5}$ Fernanda Festa, ${ }^{5}$ Katlin B. Massirer, ${ }^{5}$ and Mari C. Sogayar ${ }^{5}$

\section{Bioinformatics Groups}

Fernando Camargo Filho, ${ }^{6}$ Luiz Paulo Camargo, ${ }^{6}$ Marco A.V. Cunha, ${ }^{7}$ Sandro J. De Souza, ${ }^{8}$ Milton Faria Junior, ${ }^{6}$ Silvana Giuliatti, ${ }^{6}$ Leonardo Kopp, ${ }^{9}$ Paulo S.L. de Oliveira, ${ }^{9}$ Paulo B. Paiva, ${ }^{10}$ Anderson A. Pereira, ${ }^{6}$ Daniel G. Pinheiro, ${ }^{7}$ Renato D. Puga, ${ }^{6}$ and Jorge Estefano S. de Souza ${ }^{8}$

\section{Validation Groups}

Dulcineia M. Albuquerque, ${ }^{11}$ Luís E.C. Andrade, ${ }^{12}$ Gilson S. Baia, ${ }^{13}$ Marcelo R.S. Briones, ${ }^{14}$ Ana M.S. Cavaleiro-Luna, ${ }^{15}$ Janete

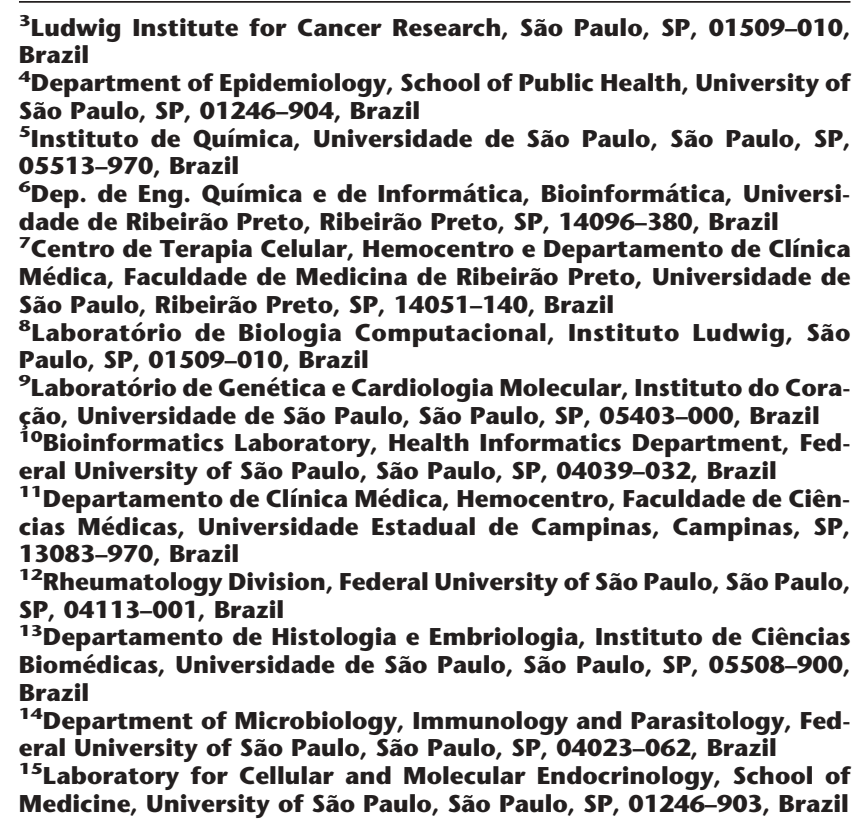


M. Cerutti, ${ }^{16}$ Fernando F. Costa, ${ }^{11}$ Eugenia Costanzi-Strauss, ${ }^{17}$ Enilza M. Espreafico ${ }^{18}$ Adriana C. Ferrasi ${ }^{19}$ Emer S. Ferro, ${ }^{13}$ Maria A.H.Z. Fortes, ${ }^{15}$ Joelma R.F. Furchi, ${ }^{20}$ Daniel GiannellaNeto, ${ }^{15}$ Gustavo H. Goldman, ${ }^{21}$ Maria H.S. Goldman, ${ }^{22}$ Arthur Gruber, ${ }^{23}$ Gustavo S. Guimarães, ${ }^{16}$ Christine Hackel, ${ }^{24}$ Flavio Henrique-Silva, ${ }^{20}$ Edna T. Kimura, ${ }^{13}$ Suzana G. Leoni, ${ }^{11}$ Cláudia Macedo, ${ }^{25}$ Bettina Malnic, ${ }^{26}$ Carina V. Manzini B.,${ }^{26}$ Suely K.N. Marie, ${ }^{27}$ Nilce M. Martinez-Rossi, ${ }^{25}$ Marcelo Menossi, ${ }^{28,29}$ Elisabete C. Miracca, ${ }^{30}$ Maria A. Nagai, ${ }^{30}$ Francisco G. Nobrega, ${ }^{31}$ Marina P. Nobrega, ${ }^{31}$ Sueli M. Oba-Shinjo, ${ }^{27}$ Márika K. Oliveira, ${ }^{18}$ Guilherme M. Orabona, ${ }^{32}$ Audrey Y. Otsuka, ${ }^{33}$ Maria L. PaçoLarson, ${ }^{18}$ Beatriz M.C. Paixão, ${ }^{7}$ Jose R.C. Pandolfi, ${ }^{34}$ Maria I.M.C. Pardini, ${ }^{19}$ Maria R. Passos Bueno, ${ }^{32}$ Geraldo A.S. Passos, ${ }^{35}$ Joao B. Pesquero, ${ }^{36}$ Juliana G. Pessoa, ${ }^{36}$ Paula Rahal, ${ }^{37}$ Cláudia A. Rainho, ${ }^{38}$ Caroline P. Reis, ${ }^{28}$ Tatiana I. Ricca, ${ }^{14}$ Vanderlei Rodrigues, ${ }^{39}$ Silvia R. Rogatto, ${ }^{38}$ Camila M. Romano, ${ }^{23}$ Janaína G. Romeiro, ${ }^{37}$ Antonio Rossi, ${ }^{39}$ Renata G. Sá, ${ }^{39}$ Magaly M. Sales, ${ }^{19}$ Simone C. Sant'Anna, ${ }^{24}$ Patrícia L. Santarosa, ${ }^{40}$ Fernando Se-

${ }^{16}$ Laboratório de Endocrinologia Molecular, Disciplina de Endocrinologia, Departamento de Medicina, Universidade Federal de São Paulo, São Paulo, 04039-002, Brazil

17Laboratório de Transferência Gênica, Instituto de Ciências Biomédicas, Universidade de São Paulo, São Paulo, SP, 05508-900, Brazil

${ }^{18}$ Departamento de Biologia Celular e Molecular e Bioagentes Patogênicos, Faculdade de Medicina de Ribeirão Preto, Universidade de São Paulo, Ribeirão Preto, SP, 14049-900, Brazil

${ }^{19}$ Laboratório de Biologia Molecular, Hemocentro, Faculdade de Medicina, Universidade Estadual Paulista, Botucatu, SP, 18618-970, Brazil

${ }^{20}$ Departamento de Genética e Evolução, Universidade Federal de São Carlos, São Carlos, SP, 13565-905, Brazil

${ }^{21}$ Faculdade de Ciências Farmacêuticas de Ribeirão Preto, Universidade de São Paulo, Ribeirão Preto, SP, 14040-903, Brazil

${ }^{22}$ Faculdade de Filosofia, Ciências e Letras de Ribeirão Preto, Universidade de São Paulo, Ribeirão Preto, SP, 14040-901, Brazil

${ }^{23}$ Depto. de Patologia, Faculdade de Medicina Veterinária e Zootecnia, Universidade de São Paulo, São Paulo, SP, 05508-000, Brazil ${ }^{24}$ Departamento de Genética Médica, Faculdade de Ciências Médicas, Universidade Estadual de Campinas, Campinas, SP, 13081-970, Brazil

${ }^{25}$ Departamento de Genética, Faculdade de Medicina de Ribeirão Preto, Universidade de São Paulo, Ribeirão Preto, SP, 14040-900, Brazil

${ }^{26}$ Departamento de Bioquímica, Instituto de Química, Universidade de São Paulo, São Paulo, SP, 05599-970, Brazil

27Departamento de Neurologia, Faculdade de Medicina, Universidade de São Paulo, São Paulo, SP, 01246-903, Brazil

${ }^{28}$ Laboratório de Genoma Funcional, Centro de Biologia Molecular e Engenharia Genética, Universidade Estadual de Campinas, Campinas, SP, 13083-970, Brazil

${ }^{29}$ Departamento de Genética e Evolução, Instituto de Biologia, Universidade Estadual de Campinas, Campinas, SP, 13084-971, Brazil ${ }^{30}$ Departamento de Radiologia, Disciplina de Oncologia, Faculdade de Medicina, Universidade de São Paulo, São Paulo, SP, 01246-903, Brazil

${ }^{31}$ Instituto de Pesquisa e Desenvolvimento, Universidade do Vale do Paraíba, São José dos Campos, SP, 12244-000, Brazil

${ }^{32}$ Departamento de Biologia, Centro de Estudos do Genoma Humano, Instituto de Biociências, Universidade de São Paulo, São Paulo, SP, 05508-900, Brazil

${ }^{33}$ Molecular Gynecology Laboratory, Gynecology Department, Federal University of São Paulo, São Paulo, SP, 04039-001, Brazil

${ }^{34}$ Department of Biological Sciences, School of Pharmacy, São Paulo State University, Araraquara, SP, 14801-902, Brazil

${ }^{35}$ Disciplina de Genética, Faculdade de Odontologia, Universidade de São Paulo, Ribeirão Preto, SP, 14040-900, Brazil

${ }^{36}$ Departamento de Biofísica, Universidade Federal de São Paulo, São Paulo, SP, 04023-062, Brazil

37Departamento de Biologia, Instituto de Biociências, Letras e Ciências Exatas, Universidade Estadual Paulista, São Jose do Rio Preto, SP 15054-000, Brazil

${ }^{38}$ Departamento de Genética, Instituto de Biociências, Universidade Estadual Paulista, Botucatu, SP, 18618-000, Brazil

${ }^{39}$ Departamento de Bioquímica e Imunologia, Faculdade de Medicina de Ribeirão Preto, Universidade de São Paulo, Ribeirão Preto, SP, 14049-900, Brazil

${ }^{40}$ Laboratório de Genética Molecular do Câncer, Departamento de gato, ${ }^{25}$ Wilson A. Silva Jr., ${ }^{7,25}$ Ismael D.C.G. Silva, ${ }^{33}$ Neusa P. Silva, ${ }^{12}$ Andrea Soares-Costa, ${ }^{20}$ Maria F. Sonati, ${ }^{41}$ Bryan E. Strauss, ${ }^{42}$ Eloiza H. Tajara, ${ }^{37}$ Sandro R. Valentini, ${ }^{34}$ Fabiola E. Villanova, ${ }^{33}$ Laura S. Ward, ${ }^{40}$ and Dalila L. Zanette ${ }^{7}$

\section{ACKNOWLEDGMENTS}

We dedicate this work to Dr. Ricardo R. Brentani (Director of the Ludwig Institute-São Paulo Branch and of the A.C. Camargo Hospital) and Dr. José Fernando Perez (Scientific Director of the São Paulo Research Foundation-FAPESP) for unconditional support and constant incentive to the Brazilian Genome Initiative. We thank Fernanda G. Barbuzano, Mário H. Bengtson, Ana P. Bogossian, Miriam S. Carmo, Christian Colin, Débora C.J. Costa, Leslie E. Ferreira, Cristiane A. Ferreira, Mariana C. Frigieri, Hellen T. Fuzii, Augusto D. Luchessi, Claudia R. Madella, Adriana A. Marques, Zizi de Mendonça, Camila C.B.O. Menezes, Alessandra Splendore, Flavia I.V. Errera, Julio C. Moreira, Irenice C. Silva, Sandra R. Souza, and Fabiana Granja for dedicated and expert technical assistance and/or critical discussions. We also thank Dr. Winston Hide and Dr. Helena Brentani for important comments and corrections on the manuscript and Juçara Parra for acting as the administrative coordinator of this project. The work was equally supported by the Ludwig Institute for Cancer Research and Fundação de Amparo à Pesquisa do Estado de São Paulo (FAPESP).

The publication costs of this article were defrayed in part by payment of page charges. This article must therefore be hereby marked "advertisement" in accordance with 18 USC section 1734 solely to indicate this fact.

\section{REFERENCES}

Adams, M.D., Kelley, J.M., Gocayne, J.D., Dubnick, M., Polymeropoulos, M.H., Xiao, H., Merril, C.R., Wu, A., Olde, B., and Moreno, R.F. 1991. Complementary DNA sequencing: Expressed sequence tags and human genome project. Science 252: 1651-1656.

Adams, M.D., Dubnick, M., Kerlavage, A.R., Moreno, R., Kelley, J.M., Utterback, T.R., Nagle, J.W., Fields, C., and Venter, J.C. 1992. Sequence identification of 2375 human brain genes. Nature 355: 632-634.

Adams, M.D., Kerlavage, A.R., Fields, C., and Venter, J.C. 1993. 3,400 new expressed sequence tags identify diversity of transcripts in human brain. Nat. Genet. 4: 256-267.

Bailey, L.C., Searls Jr., D.B., and Overton, G.C. 1998. Analysis of EST-driven gene annotation in human genomic sequence. Genome Res. 8: $362-376$.

Batzoglou, S., Pachter, L., Mesirov, J.P., Berger, B., and Lander, E.S. 2000. Human and mouse gene structure: Comparative analysis and application to exon prediction. Genome Res. 10: 950-958.

Beaudoing, E. and Gautheret, D. 2001. Identification of alternate polyadenylation sites and analysis of their tissue distribution using EST data. Genome Res. 11: 1520-1526.

Bonaldo, M.F., Lennon, G., and Soares, M.B. 1996. Normalization and subtraction: Two approaches to facilitate gene discovery. Genome Res. 6: 791-806.

Bortoluzzi, S., d'Alessi, F., and Danieli, G.A. 2000a. A computational reconstruction of the adult human heart transcriptional profile. $J$ Mol. Cell. Cardiol. 32: 1931-1938.

. 2000b. A novel resource for the study of genes expressed in the adult human retina. Invest. Ophthalmol. Vis. Sci. 41: 3305-3308.

Bortoluzzi, S., d'Alessi, F., Romualdi, C., and Danieli, G.A. 2000c. The human adult skeletal muscle transcriptional profile reconstructed by a novel computational approach. Genome Res. 10: 344-349.

Brett, D., Hanke, J., Lehmann, G., Haase, S., Delbruck, S., Krueger, S., Reich, J., and Bork, P. 2000. EST comparison indicates 38\% of human mRNAs contain possible alternative splice forms. FEBS Lett. 474: 83-86.

Camargo, A.A., Samaia, H.P., Dias-Neto, E., Simao, D.F., Migotto, I.A.,

Clínica Médica, Faculdade de Ciências Médicas, Universidade Estadual de Campinas, Campinas, SP, 13083-970, Brazil

${ }^{41}$ Departamento de Patologia Clínica, Faculdade de Ciências Médicas, Universidade Estadual de Campinas, Campinas, SP, 13083-970, Brazil

${ }^{42}$ Setor de Vetores Virais, Laboratório de Cardiologia Molecular, Instituto do Coração, Faculdade de Medicina, Universidade de São Paulo, São Paulo, SP, 05403-000, Brazil 
Briones, M.R., Costa, F.F., Nagai, M.A., Verjovski-Almeida, S., Zago, M.A., et al. 2001. The contribution of 700,000 ORF sequence tags to the definition of the human transcriptome. Proc. Natl. Acad. Sci. 98: $12103-12108$

Camargo, A.A., de Souza, S.J., Brentani, R.R., and Simpson, A.J. 2002. Human gene discovery through experimental definition of transcribed regions of the human genome. Curr. Opin. Chem. Biol. 6: $13-16$.

Carninci, P., Shibata, Y., Hayatsu, N., Sugahara, Y., Shibata, K., Itoh, M., Konno, H., Okazaki, Y., Muramatsu, M., and Hayashizaki, Y. 2000. Normalization and subtraction of cap-trapper-selected cDNAs to prepare full-length cDNA libraries for rapid discovery of new genes. Genome Res. 10: 1617-1630.

Chirgwin, J.M., Przybyla, A.E., MacDonald, R.J., and Rutter WJ. 1979. Isolation of biologically active ribonucleic acid from sources enriched in ribonuclease. Biochemistry 18: 5294-5299.

Clark, F. and Thanaraj, T.A. 2002. Categorization and characterization of transcript-confirmed constitutively and alternatively spliced introns and exons from human. Hum. Mol. Genet. 11: 451-464.

Clifford, R., Edmonson, M., Hu, Y., Nguyen, C., Scherpbier, T., and Buetow, K.H. 2000. Expression-based genetic/physical maps of single-nucleotide polymorphisms identified by the cancer genome anatomy project. Genome Res. 10: 1259-1265.

Dennis, C. 2001. Tiled arrays for gene hunting. Nat. Rev. Genet. 2: 161

Dias, N.E., Garcia, C.R., Verjovski-Almeida, S., Briones, M.R., Nagai, M.A., da Silva Jr., W., Zago, M.A., Bordin, S., Costa, F.F., Goldman, G.H., et al. 2000. Shotgun sequencing of the human transcriptome with ORF expressed sequence tags. Proc. Natl. Acad. Sci. 97: 3491-3496.

Dunham, I., Shimizu, N., Roe, B.A., Chissoe, S., Hunt, A.R., Collins, J.E., Bruskiewich, R., Beare, D.M., Clamp, M., Smink, L.J., et al. 1999. The DNA sequence of human chromosome 22. Nature 402: 489-495.

Ewing, B. and Green, P. 1998. Base-calling of automated sequencer traces using phred, II: Error probabilities. Genome Res. 8: 186-194. - 2000. Analysis of expressed sequence tags indicates 35,000 human genes. Nat. Genet. 25: 232-234.

Ewing, B., Hillier, L., Wendl, M.C., and Green, P. 1998. Base-calling of automated sequencer traces using phred, I: Accuracy assessment. Genome Res. 8: 175-185.

Florea, L., Hartzell, G., Zhang, Z., Rubin, G.M., and Miller, W. 1998. A computer program for aligning a cDNA sequence with a genomic DNA sequence. Genome Res. 8: 967-974.

Garg, K., Green, P., and Nickerson, D.A. 1999. Identification of candidate coding region single nucleotide polymorphisms in 165 human genes using assembled expressed sequence tags. Genome Res 9: 1087-1092.

Gautheret, D., Poirot, O., Lopez, F., Audic, S., and Claverie, J.M. 1998. Alternate polyadenylation in human mRNAs: A large-scale analysis by EST clustering. Genome Res. 8: 524-530.

Hattori, M., Fujiyama, A., Taylor, T.D., Watanabe, H., Yada, T., Park, H.S., Toyoda, A., Ishii, K., Totoki, Y., Choi, D.K., et al. 2000. The DNA sequence of human chromosome 21. Nature 405: 311-319.

Hide, W.A., Babenko, V.N., van Heusden, P.A., Seoighe, C., and Kelso, J.F. 2001. The contribution of exon-skipping events on chromosome 22 to protein coding diversity. Genome Res. 11: 1848-1853.

Hu, G., Modrek, B., Riise Stensland, H.M., Saarela, J., Pajukanta, P., Kustanovich, V., Peltonen, L., Nelson, S.F., and Lee, C. 2002. Efficient discovery of single-nucleotide polymorphisms in coding regions of human genes. Pharmacogenomics J. 2: 236-242.

Hudson, T.J., Colbert, A.M., Reeve, M.P., Bae, J.S., Lee, M.K., Nussbaum, R.L., Budarf, M.L., Emanuel, B.S., and Foote, S. 1994. Isolation and regional mapping of 110 chromosome 22 STSs. Genomics 24: $588-592$.

Huminiecki, L. and Bicknell, R. 2000. In silico cloning of novel endothelial-specific genes. Genome Res. 10: 1796-1806.

Irizarry, K., Kustanovich, V., Li, C., Brown, N., Nelson, S., Wong, W., and Lee, C.J. 2000. Genome-wide analysis of single-nucleotide polymorphisms in human expressed sequences. Nat. Genet. 26: $233-236$.

Iseli, C., Stevenson, B.J., de Souza, S.J., Samaia, H.B., Camargo, A.A., Buetow, K.H., Strausberg, R.L., Simpson, A.J., Bucher, P., and Jongeneel, C.V. 2002. Long-range heterogeneity at the $3^{\prime}$ ends of human mRNAs. Genome Res. 12: 1068-1074.

Jiang, J. and Jacob, H.J. 1998. EbEST: An automated tool using expressed sequence tags to delineate gene structure. Genome Res. 8: 268-275.

Kan, Z., Rouchka, E.C., Gish, W.R., and States, D.J. 2001. Gene structure prediction and alternative splicing analysis using genomically aligned ESTs. Genome Res. 11: 889-900.

Kan, Z., States, D., and Gish, W. 2002. Selecting for functional alternative splices in ESTs. Genome Res. 12: 1837-1845.

Kapranov, P., Cawley, S.E., Drenkow, J., Bekiranov, S., Strausberg, R.L., Fodor, S.P., and Gingeras, T.R. 2002. Large-scale transcriptional activity in chromosomes 21 and 22. Science 296: 916-919.

Katsanis, N., Worley, K.C., Gonzalez, G., Ansley, S.J., and Lupski, J.R. 2002. A computational/functional genomics approach for the enrichment of the retinal transcriptome and the identification of positional candidate retinopathy genes. Proc. Natl. Acad. Sci. 99: 14326-14331.

Kent, W.J., Sugnet, C.W., Furey, T.S., Roskin, K.M., Pringle, T.H., Zahler, A.M., and Haussler, D. 2002. The human genome browser at UCSC. Genome Res. 12: 996-1006.

Kikuno, R., Nagase, T., Waki, M., and Ohara, O. 2002. HUGE: A database for human large proteins identified in the Kazusa cDNA sequencing project. Nucleic Acids Res. 30: 166-168.

Lander, E.S., Linton, L.M., Birren, B., Nusbaum, C., Zody, M.C., Baldwin, J., Devon, K., Dewar, K., Doyle, M., FitzHugh, W., et al. 2001. Initial sequencing and analysis of the human genome. Nature 409: 860-921.

Lee, Y., Sultana, R., Pertea, G., Cho, J., Karamycheva, S., Tsai, J., Parvizi, B., Cheung, F., Antonescu, V., White, J., et al. 2002. Cross-referencing eukaryotic genomes: TIGR Orthologous Gene Alignments (TOGA). Genome Res. 12: 493-502.

Liang, F., Holt, I., Pertea, G., Karamycheva, S., Salzberg, S.L., and Quackenbush, J. 2000. Gene index analysis of the human genome estimates approximately 120,000 genes. Nat. Genet. 25: 239-240.

Megy, K., Audic, S., and Claverie, J.M. 2003. Positional clustering of differentially expressed genes on human chromosomes 20,21 and 22. Genome Biol. 4: P1.

Modrek, B., Resch, A., Grasso, C., and Lee, C. 2001. Genome-wide detection of alternative splicing in expressed sequences of human genes. Nucleic Acids Res. 29: 2850-2859.

Nakajima, D., Okazaki, N., Yamakawa, H., Kikuno, R., Ohara, O., and Nagase, T. 2002. Construction of expression-ready cDNA clones for KIAA genes: Manual curation of 330 KIAA cDNA clones. DNA Res. 9: $99-106$

Penn, S.G., Rank, D.R., Hanzel, D.K., and Barker, D.L. 2000. Mining the human genome using microarrays of open reading frames. Nat. Genet. 26: $315-318$.

Phillips, R.L., Ernst, R.E., Brunk, B., Ivanova, N., Mahan, M.A., Deanehan, J.K., Moore, K.A., Overton, G.C., and Lemischka, I.R. 2000. The genetic program of hematopoietic stem cells. Science 288: $1635-1640$.

Picoult-Newberg, L., Ideker, T.E., Pohl, M.G., Taylor, S.L., Donaldson, M.A., Nickerson, D.A., and Boyce-Jacino, M. 1999. Mining SNPs from EST databases. Genome Res. 9: 167-174.

Reymond, A., Camargo, A.A., Deutsch, S., Stevenson, B.J., Parmigiani, R.B., Ucla, C., Bettoni, F., Rossier, C., Lyle, R., Guipponi, M., et al. 2002. Nineteen additional unpredicted transcripts from human chromosome 21. Genomics 79: 824-832.

Roest, C.H., Jaillon, O., Bernot, A., Dasilva, C., Bouneau, L., Fischer, C., Fizames, C., Wincker, P., Brottier, P., Quetier, F., et al. 2000. Estimate of human gene number provided by genome-wide analysis using Tetraodon nigroviridis DNA sequence. Nat. Genet. 25: 235-238.

Shoemaker, D.D., Schadt, E.E., Armour, C.D., He, Y.D., Garrett-Engele, P., McDonagh, P.D., Loerch, P.M., Leonardson, A., Lum, P.Y., Cavet, G., et al. 2001. Experimental annotation of the human genome using microarray technology. Nature 409: 922-927.

Silva, A.P., Salim, A.C., Bulgarelli, A., de Souza, J.E., Osorio, E., Caballero, O.L., Iseli, C., Stevenson, B.J., Jongeneel, C.V., de Souza, S.J., et al. 2003. Identification of 9 novel transcripts and two RGSL genes within the hereditary prostate cancer region (HPC1) at 1q25. Gene 310: $49-57$.

Sorek, R. and Safer, H.M. 2003. A novel algorithm for computational identification of contaminated EST libraries. Nucleic Acids Res. 31: 1067-1074.

Strausberg, R.L., Feingold, E.A., Klausner, R.D., and Collins, F.S. 1999. The mammalian gene collection. Science 286: $455-457$.

Strausberg, R.L., Buetow, K.H., Emmert-Buck, M.R., and Klausner, R.D. 2000. The cancer genome anatomy project: Building an annotated gene index. Trends Genet. 16: 103-106.

Strausberg, R.L., Feingold, E.A., Grouse, L.H., Derge, J.G., Klausner, R.D., Collins, F.S., Wagner, L., Shenmen, C.M., Schuler, G.D., Altschul, S.F., et al. 2002. Generation and initial analysis of more than 15,000 full-length human and mouse cDNA sequences. Proc. Natl. Acad. Sci. 99: 16899-16903.

Tugendreich, S., Bassett Jr., D.E., McKusick, V.A., Boguski, M.S., and Hieter, P. 1994. Genes conserved in yeast and humans. Hum. Mol. Genet. 3: 1509-1517.

Venter, J.C., Adams, M.D., Myers, E.W., Li, P.W., Mural, R.J., Sutton, G.G., Smith, H.O., Yandell, M., Evans, C.A., Holt, R.A., et al. 2001 The sequence of the human genome. Science 291: 1304-1351.

Wang, Z., Lo, H.S., Yang, H., Gere, S., Hu, Y., Buetow, K.H., and Lee, M.P. 2003. Computational analysis and experimental validation of tumor-associated alternative RNA splicing in human cancer. Cancer

\section{Genome Research}


Res. 63: 655-657.

Wiemann, S., Weil, B., Wellenreuther, R., Gassenhuber, J., Glassl, S., Ansorge, W., Bocher, M., Blocker, H., Bauersachs, S., Blum, H., et al. 2001. Toward a catalog of human genes and proteins: Sequencing and analysis of 500 novel complete protein coding human cDNAs. Genome Res. 11: 422-435.

Williamson, A.R. 1999. The Merck Gene Index project. Drug Discov. Today 4: 115-122.

Xie, H., Zhu, W.Y., Wasserman, A., Grebinskiy, V., Olson, A., and Mintz, L. 2002. Computational analysis of alternative splicing using EST tissue information. Genomics 80: 326-330.

$\mathrm{Xu}$, Q., Modrek, B., and Lee, C. 2002. Genome-wide detection of tissue-specific alternative splicing in the human transcriptome. Nucleic Acids Res. 30: 3754-3766.

Yelin, R., Dahary, D., Sorek, R., Levanon, E.Y., Goldstein, O., Shoshan, A., Diber, A., Biton, S., Tamir, Y., Khosravi, R., et al. 2003. Widespread occurrence of antisense transcription in the human genome. Nat. Biotechnol. 21: 379-386.

Yu, Y., Zhang, C., Zhou, G., Wu, S., Qu, X., Wei, H., Xing, G., Dong, C., Zhai, Y., Wan, J., et al. 2001. Gene expression profiling in human fetal liver and identification of tissue- and developmental-stage-specific genes through compiled expression profiles and efficient cloning of full-length cDNAs. Genome Res. 11: $1392-1403$.

\section{WEB SITE REFERENCES}

http://www.ncbi.nlm.nih.gov/entrez/query.fcgi?db=unigene; Unigene home page.

http://www.atcc.org; American Type Culture Collection home page. http://www.ncbi.nlm.nih.gov/refseq; RefSeq home page.

http://www.repeatmasker.org; RepeatMasker program.

http://genome.ucsc.edu/cgi-bin/hgBlat; University of California Santa Cruz, Genome Browser.

http://200.18.51.201/viewtfi; Information related to TFUs selected for experimental validation.

http://200.18.51.201/transcript/Participants.html; Full list of participant groups of The Ludwig-FAPESP Transcript Finishing Initiative.

http://200.18.51.201/viewconsensus; Access to consensus sequences generated for validated TFUs.

Received October 23, 2003; accepted in revised form March 12, 2004. 


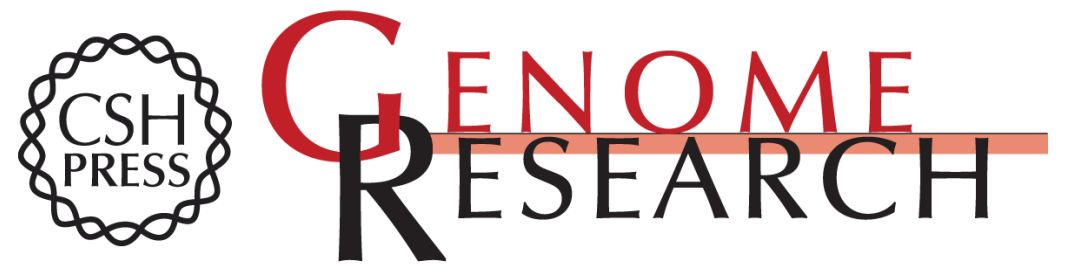

\section{A Transcript Finishing Initiative for Closing Gaps in the Human Transcriptome}

The Ludwig-FAPESP Transcript Finishing Initiative, Mari Cleide Sogayar and Anamaria A. Camargo

Genome Res. 2004 14: 1413-1423

Access the most recent version at doi:10.1101/gr.2111304

Supplemental Material

References

License

Email Alerting Service
http://genome.cshlp.org/content/suppl/2004/07/02/2111304.DC1

This article cites 65 articles, 33 of which can be accessed free at: http://genome.cshlp.org/content/14/7/1413.full.html\#ref-list-1

Receive free email alerts when new articles cite this article - sign up in the box at the top right corner of the article or click here.

\section{Affordable, Accurate Sequencing.}

To subscribe to Genome Research go to: https://genome.cshlp.org/subscriptions 